Selcuk Journal of Agriculture and Food Sciences

$\underline{\text { http://sjafs.selcuk.edu.tr/sjafs/index }}$

Research Article
SJAFS

(2021) 35 (2), 161-169

e-ISSN: $2458-8377$

DOI:10.15316/SJAFS.2021.244

\title{
Determination of Vortex and Critical Submergence of Submersible Pumps
}

\section{iD Nuri ORHAN}

Selçuk University, Faculty of Agriculture, Department of Agricultural Machinery and Technologies Engineering, Konya, Turkey

\begin{tabular}{l}
\hline ARTICLE INFO \\
\hline Article history: \\
Received date: 01.07 .2021 \\
Accepted date: 13.07 .2021 \\
\hline
\end{tabular}

\section{Keywords:}

Critical submergence

Vortex submergence

Submergence

Submersible pumps

Deep well

\begin{abstract}
In this study, submergence vortex and critical submergence of submersible pumps were investigated at different pump nominal diameters and water inlet crosssections. Experiments were conducted with submersible pumps with three different outside diameters. For each pump, outlet pressure and inlet pressure measurements were performed at three different water inlet cross-sections, five different flow rates and different submergence.

Present findings revealed that for all three nominal diameters and cross-sections, critical submergence increased with increasing flow rates. The greatest critical submergence depth $(1000 \mathrm{~mm})$ was obtained from 3 " pumps and the smallest critical submergence depth $(10 \mathrm{~mm})$ was obtained from $5 "$ pump. Critical submergence increased with decreasing cross-sections. It was determined that there was an inverse relationship between the pump nominal diameter and the critical immersion depth. The critical dipping decreased with the increase of the pump nominal diameter. Critical submergence obtained at original cross-sections of submersible pumps were compared with the aid of a developed momentum equilibrium equation. The experiments were determined the submergence of vortex and vortex types. The vortex that occurred in all pump tests formed generally below the critical submergence.
\end{abstract}

\section{Introduction}

Since two different methods are used for power transmission to deep well pumps, there are two types of deep well pumps: vertical shaft deep well pumps and submersible deep well pumps. A typical submersible pump placed within the well, basic height terms, and well characteristics is presented in Figure 1.

\section{Critical Submergence}

The vertical distance between the pump water inlet and the dynamic water surface is defined as "submergence" (S). If the submergence is less than critical submergence $(\mathrm{Sc})$, then a vortex is generated. As a result, the pump loses suction, and the efficiency decreases (Khanarmuei et al. 2018; Sarkardeh 2017a). Generally, critical submergence is associated with Sc / D (Eswaran et al. 2007; Khanarmuei et al. 2018; Ott 1995).

Most of the researchers have attempted to estimate critical submergence (Hite Jr and Mih 1994; Sarkardeh et al. 2010; Travis and Mays 2010; Yildırım et al. 2012). Critical submergence in open canal flows and tanks were generally calculated with the aid of various empirical relationships (Ahmad et al. 2004;

Corresponding author email: nuriorhan@selcuk.edu.tr This article was derived from the author's Ph.D. Thesis
Khanarmuei et al. 2018; Sarkardeh 2017a; Yildirim and Kocabaş 1998; 2002; Yıldırım et al. 2000).

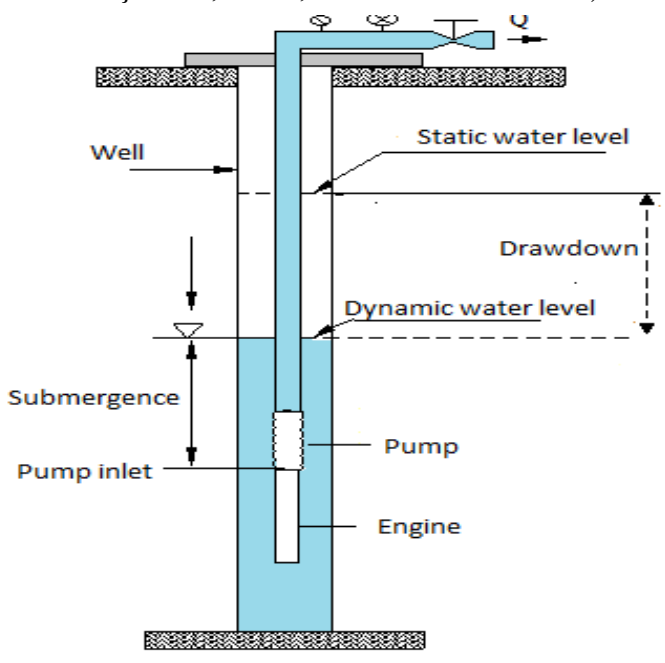

Figure 1

Deep well characteristic curve and basic height terms

There is no clear literature on the level of submergence during submersible pumps of well placing (Schulz 2013). Maximum $5 \mathrm{~m}$ submergences propose for vertical shaft deep well pumps.

It was stated in a study carried out in Konya province of Turkey that submergence of vertical shaft deep 
well pumps was quite above the ordinary values $(5 \mathrm{~m}$ below the dynamic level). Submergence in deep well pumping irrigations was $20 \%$ deeper in $18 \%, 20-40 \%$ deeper in $47 \%$ and more than $40 \%$ deeper in $35 \%$ of the irrigations. (Çalışır and Konak 1998).

\section{Submergence Vortex}

Vortex is moving whirl generated by turning and pitting of water or air. The vortex frequently occurs in pump-intake due to unfavorable flow conditions or low submergence (Chen et al. 2012). The center of the vortex is appeared sharply after increasing the power of the vortex (Kirst et al. 2010). The potential of the vortex and air-inlet vortex at the pump-intake is changed by depending on the mean value of flow velocity and submergence. In the case of the formation of vortex depending on the depth of submergence, determination of the beginning of vortex is important for the observation of the various types of the vortex. The economic life and efficiency of the pump are affected by the interaction of the wings of the pump and air when the vortex occurs (Nagahara et al. 2001; Yildirim et al. 2011). If the air enters the pump after the formation of the vortex, there can exist cavitation (Okamura and Kamemoto 2005).

According to different energy levels, vortex formations are classified and shown in Figure 2 . Sarkardeh et al. (2010) generally divided vortex into three classes. In their study, they defined a class $\mathrm{C}$ vortex as safe, class B vortex trash, and class A vortexes as dangerous. Knauss (2017) explained that vortices which occur in class 1 and 2 do not affect the operation of pumps. They reported that the vortices formed in classes 3,4,5 and 6 are dangerous.

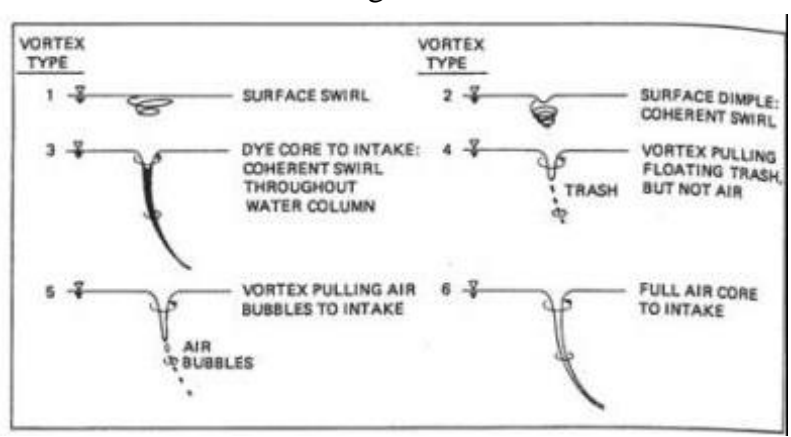

Figure 2

Vortex classification (Knauss, 2017)

Vortex in different shapes consists of a pump intake or suction line at the entrance with the decreasing water level (Azarpira, et al., 2014; Okamura et al. 2007). Okamura et al. (2007) reported that different vortex types occur at $230 \mathrm{~mm}$ water level in their study at a constant flow rate, while a continuous air inlet vortex occurs at $150 \mathrm{~mm}$ water level.

The pump manufacturers and installers usually do not take the risk of low submergence and thus they generally keep submergence as high as possible. As a result of this tons of processed material (column pipe) are unnecessarily submerged into waters, then investment costs increase, and operational costs increase because of redundant frictional losses. Such a case ultimately results in significant economic losses for both the facilities and the country. It is also possible to add installation labor and time spend for these operations to these losses.

In this study, critical submergence for submersible pumps to be placed in deep wells was tried to be determined and the basic factors affecting this critical depth were investigated.

The submersible pumps have determined the depth of formation of vortices and vortex type. For this purpose, submersible pumps were tested with the aid special testing setup at 3 different nominal diameters $\left(D_{1}\right.$, $\mathrm{D}_{2}$ and $\mathrm{D}_{3}$ ), 3 different water intake cross-sections $\left(\mathrm{CS}_{1}, \mathrm{CS}_{2}\right.$ and $\left.\mathrm{CS}_{3}\right), 5$ different flow rates $(\mathrm{Q})$ and 5 different submergence $(\mathrm{S})$. The parameters of outlet pressure $(\mathrm{Po})$, inlet pressure $(\mathrm{Pe})$, flow rate $(\mathrm{Q})$, temperatures and relative humidity values were measured. To identify types of vortices were used cameras. With the resultant data, basic values for submergence of deep well pumps were put forth. Resultant critical submergence was compared with the developed momentum equilibrium equation.

\section{Material and Method}

\subsection{Material}

Experiments were conducted at Deep Well Test Unit of Prof. Dr. Şinasi YETKIN Practice Workshop in Agricultural Machinery and Technologies Engineering Department of Selcuk University Agricultural Faculty (Figure 3).

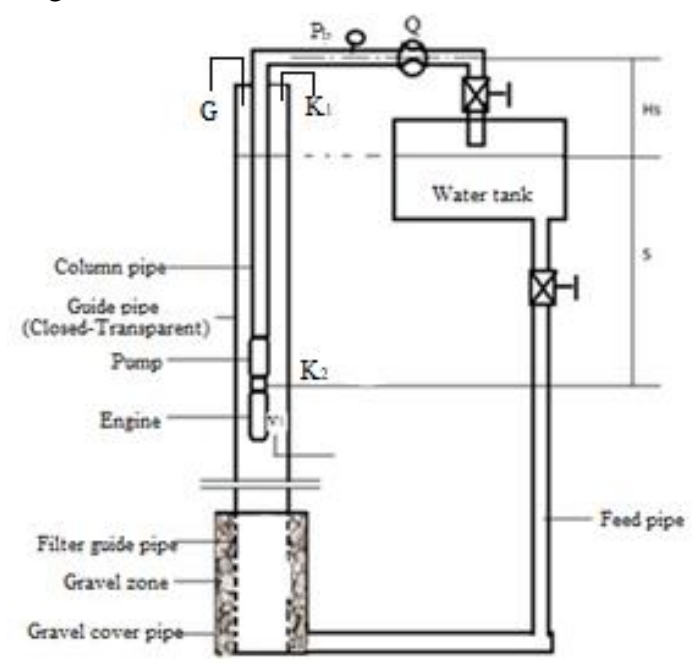

Figure 3

Deep Well Pump Test Tower and Installations

The test setup with a deep well has a total height of 10 $\mathrm{m}$. From the bottom to top, the unit has $2 \mathrm{~m}$ oblong perforated filter guide pipe, $4 \mathrm{~m}$ closed guide pipe, $4 \mathrm{~m}$ transparent guide pipe. Perforated filter guide pipe is surrounded by $10 \mathrm{~cm}$ wide gravel layer with a bulk density of $1,54 \mathrm{~kg} \mathrm{~m}^{-3}, 7-15 \mathrm{~mm}$ geometric diameter. Technical specifications for the submersible deep well pumps used in the present experiments are provided in 
Table 1. For pump actuation, $4 \mathrm{~kW}$ motor was used for $\mathrm{D}_{1}$ pump, and $5.5 \mathrm{~kW}$ motors were used for $\mathrm{D}_{2}$ and $\mathrm{D}_{3}$ pumps. Technical specifications for measurement deTable 1

Technical specifications for submersible pumps vices used in the present experiments are provided in Table 2.

\begin{tabular}{lccc}
\hline Technical specifications & $\mathrm{D}_{1}$ & $\mathrm{D}_{2}$ & $\mathrm{D}_{3}$ \\
\hline Pump outside diameter $(\mathrm{mm})$ & 152.4 & 177.8 & 203.2 \\
Pump material (TSE EN 1591) & Cast iron & Cast iron & Cast iron \\
Pump impeller material & Brass & Brass & Brass \\
Pump shaft material & Stainless steel & Stainless steel & Stainless steel \\
Inlet cross section $\left(\mathrm{KA}_{2}\right)\left(\mathrm{mm}^{2}\right)$ & 7200 & 9000 & 10800 \\
Pump shaft diameter $(\mathrm{mm})$ & 25 & 25 & 30 \\
Pump number of stages & 2 & 1 & 1 \\
Number of blades & 5 & 7 & 6 \\
Blade thickness $(\mathrm{mm})$ & 5 & 5 & 5 \\
Impeller outlet diameter $(\mathrm{mm})$ & 94.5 & 140 & 150 \\
Impeller outlet width $(\mathrm{mm})$ & 15 & 16 & 20 \\
\hline
\end{tabular}

Inlet pressure (vacuum) was measured with the aid of a mercurial U-tube differential manometer installed at the bottom of the suction nozzle. The U-pipe differential manometer, $6 \mathrm{~mm}$ diameter, $2 \mathrm{~m}$ long transparent hose and $200 \mathrm{~g}$ mercury were used. Manometer installation is presented in Figure 5.

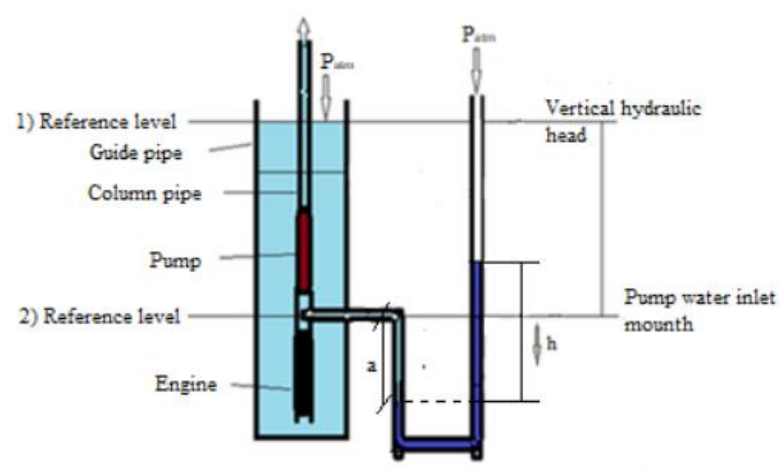

Figure 4

U-tube differential manometer

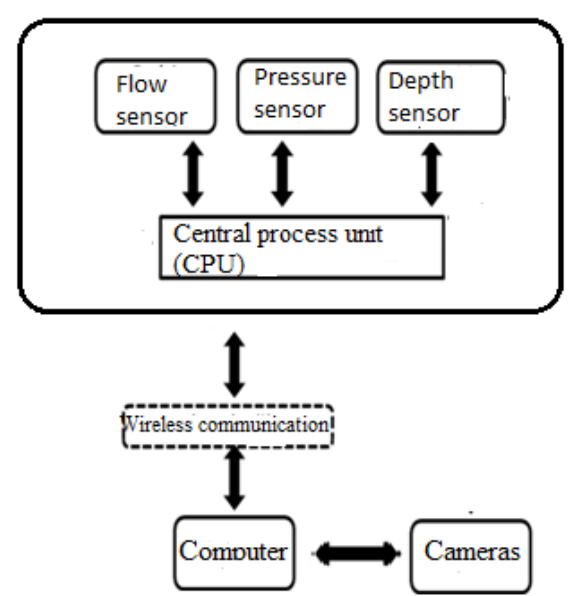

Figures 5

Block diagram of the automation system
Table 2

Technical specifications for measurement devices

\begin{tabular}{|c|c|}
\hline Device & Technical specifications \\
\hline Flow meter & $\begin{array}{c}\text { S MAG } 100 \text { TIP, DN 80-100-125 } \\
\text { flange connection electromagnetic } \\
\text { flow meter, } 220 \mathrm{~V} \text { supplied digital } \\
\text { indicator, instant flow, percent flow, } \\
\text { total flow indicators. Adjustable } 4-20 \\
\text { m/A plus and frequency output. Mea- } \\
\text { surement error: } 0.5 \% \text {. }\end{array}$ \\
\hline $\begin{array}{l}\text { Electric } \\
\text { Machine }\end{array}$ & $\begin{array}{c}\text {-Suver, } 380 \mathrm{~V}, 8.2 \mathrm{~A}, 50 \mathrm{~Hz}, 2869 \\
1 / \mathrm{min}, 4,5 \mathrm{~kW} \text {, shaft diameter }: 25 \mathrm{~mm} \text {, } \\
\text { water-cooler, } 3 \times 2.5 \mathrm{~mm}^{2} \text { cable cross- } \\
\text { section } \\
\text {-Watermot, } 380 \mathrm{~V}, 13.6 \mathrm{~A}, 50 \mathrm{~Hz}, \\
27801 / \mathrm{min}, 5,5 \mathrm{~kW} \text {, shaft diameter }: 25 \\
\text { mm, water-cooler, } 3 \times 2.5 \mathrm{~mm}^{2} \text { cable } \\
\text { cross-section }\end{array}$ \\
\hline $\begin{array}{l}\text { Water level } \\
\text { meter }\end{array}$ & $\begin{array}{l}\text { Hydrotechnik brand, } 010 \text { type/1,5 V, } \\
150 \mathrm{~m} \text { scaled cable, voice and light } \\
\text { indicator type. }\end{array}$ \\
\hline $\begin{array}{l}\text { Temperature } \\
\text { sensors }\end{array}$ & $\begin{array}{l}\text { Turck brand, 10-24 VDC, }-50 \ldots 100 \\
\text { 0C, } 4-20 \mathrm{~mA} \text { output. }\end{array}$ \\
\hline Cameras & $\begin{array}{c}\text { Radial axis camera; } 1080 \mathrm{p} \text { HD Sensor, } \\
720 \mathrm{p} \text { HD video } \\
\text { Axial axis camera; } 15.0 \text { megapixels, } \\
\text { Full HD video recording }\end{array}$ \\
\hline Computer & Asus intel core i7. \\
\hline
\end{tabular}

\subsection{Method}

A software and automation system was developed to record the measured quantities. The block diagram of the system is presented in Figure 5. The sensor data are transferred to a computer through a wireless communication card. The information stored at the central processing unit was recorded by an operator at desired intervals and with proper names through a software interface. The recording process was arranged so as to get data in every second. The records was initiated after the pump regime and 50 data were received from a sensor. 
Measurements at optimum operating speed were taken at 5-7 different dynamic water levels of 5 different flow rates. Initial values were recorded through operating the pump at a specified flow rate and then submergence depth was reduced. The flow rate altered with the descending water level was restored with the valve over the measurement pipe. In this way, measurements were recorded for 5 different submergence heights of each flow rate.

TS EN ISO 9906 standard was taken into consideration in the measurement of pump operating characteristics and relevant calculations (Anonim, 2014).

Experiments were conducted at $1880 \mathrm{~mm}$ pump submergence (constant hydraulic head). Drawdown was measured with a water level meter and submergence was calculated with the aid of Equation 1;

$$
S=1880-\Delta
$$

Where; $\mathrm{S}=$ Submergence depth $(\mathrm{mm})$ and $\Delta=$ Depression (mm).

Additional to the original inlet cross sections of the pumps, an adapter was used to increase cross-section. A ring was installed on the adapter to get a smaller cross-section (Figure 6). Cross-sections are provided in Table 3.

Different cross-sections were achieved by placing inlet adaptors without altering the cross-section shape.
An adapter was supplied for each nominal diameter (a total of 6 adapters). One of these adapters was used as an original cross-section $\left(\mathrm{CS}_{2}\right)$ inlet adaptor. The other adaptors provided either $20 \%$ larger cross-section $\left(\mathrm{CS}_{3}\right)$ and $20 \%$ smaller cross-section $\left(\mathrm{CS}_{1}\right)$. The experimental design of the pumps is given in Figure 7.

Table 3

Pump inlet cross-sections $\left(\mathrm{mm}^{2}\right)$

\begin{tabular}{lccc}
\hline Pumps & $\begin{array}{c}\mathrm{CS}_{1} \\
\text { (20\% smaller) }\end{array}$ & $\begin{array}{c}\mathrm{CS}_{2} \\
\text { (Original) }\end{array}$ & $\begin{array}{c}\mathrm{CS}_{3} \\
(20 \% \text { greater })\end{array}$ \\
\hline $\mathrm{D}_{1}$ & 3800 & 4800 & 5800 \\
$\mathrm{D}_{2}$ & 7200 & 9000 & 10800 \\
$\mathrm{D}_{3}$ & 13500 & 16800 & 20000 \\
\hline
\end{tabular}

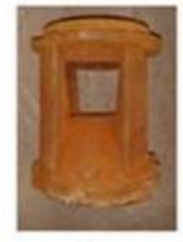

a

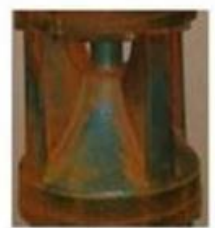

b

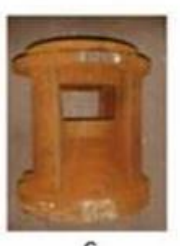

Figures 6

Cross-section alteration ring placed at inlet adapters of the pump (a; \%20 large adaptor, b; Orginal adaptor, c; $\% 20$ smaller adaptor)

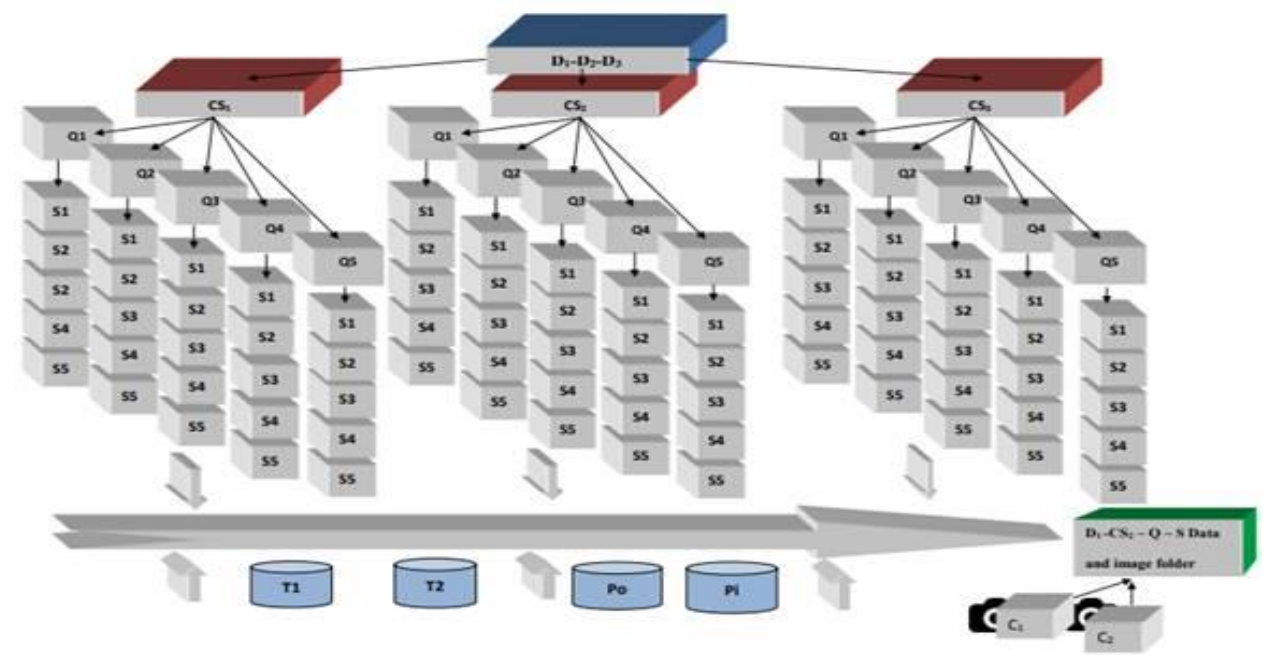

Figures 7

Experimental design for submersible pumps

\subsection{Determination of critical submergence}

Critical submergence (Sc) was determined by taking the pressure measured at the pump inlet axis as explained below for a specific criterion.

Pump inlet pressure was determined with the aid of the U-pipe differential monometer installed at the pump inlet. As can be seen in Figure 5, the height $\mathrm{h}$ between the mercury level at the right arm of the Upipe differential manometer and number 2 reference level was measured and recorded. Before the operation of the pump, the height $h$ is equal to the vertical hydraulic head and submergence depth is at the maximum level. With the operation of the pump, the height $h$ decreases with the increasing suction based on flow rate. Following the zero value of the $h$, vacuum pressure is created at the pump suction. Then, positive hydraulic heat at the guide pipe will not be able to compensate suction head at the pump inlet. The continuation of the decrease will continue the increase in the vacuum pressure. Further reduction of the drop may cause air to enter the pump. The $h$ values were measured in $\mathrm{mm}$ in three replicates. With these $\mathrm{h}$ values, pressure at the pump inlet was calculated by using the following equation;

$\mathrm{P}_{\mathrm{e}}=\frac{\rho_{\mathrm{m}} \mathrm{g}(\mathrm{h} / 1000)-\rho_{\mathrm{m}} \mathrm{g}(\mathrm{a} / 1000)}{1000}(\mathrm{kPa})$ 
Where; mercury density $\rho_{\mathrm{m}}=13600 \mathrm{~kg} \mathrm{~m}^{-3}$ and gravitational acceleration $\mathrm{g}=9.81 \mathrm{~m} \mathrm{~s}^{-2}$.

Then at constant flow rates, from the regression equations obtained from Pe equation as a function of submergence depth, the submergence (S) making the Pe value zero was determined, and they were taken as critical submergence $(\mathrm{Sc})$.

Flow rates were measured from two different points of the experimental setup (Figure 3).

\subsection{Theoretical minimum submergence with equilibri- um equation of linear momentum}

Conversion of mechanical energy into hydraulic energy in centrifugal pumps is explained by the Euler equation obtained by taking the momentum of angular momentum. Moving from this principle, an equation was obtained for theoretical minimum submergence $\left(\mathrm{S}_{\mathrm{T}}\right)$ by writing the equilibrium equation of linear momentum as schematically presented in Figure 8 within the scope of preservation of momentum by taking the position of submersible pump in the well and water flow into consideration. In that equation, $F_{1}$ is the upward thrust of pumped water, $\mathrm{F}_{2}$ is the downward water head at the pump suction inlet. At equilibrium, $F_{1}=F_{2}$, but $F_{2}>F_{1}$ is required for the theoretical operation of deep well pumps. According to this approach, the equation was written and reduced as follows. In the last equation, $\mathrm{Ak}\left(\mathrm{m}^{2}\right)$ is an inner cross-section of the pump column pipe, $\mathrm{Ah}\left(\mathrm{m}^{2}\right)$ is a cross-section of the ring between well guide pipe and pump column pipe and $\mathrm{v}$ $\left(\mathrm{m} \mathrm{s}^{-1}\right)$ is the mean water flow rate in column pipe.

$\mathrm{Q}=\mathrm{A}_{\mathrm{k}}{ }^{*} \mathrm{v}$ and $\mathrm{F}_{1}=\rho^{*} \mathrm{Q}^{*} \mathrm{v}$

then

$\mathrm{F}_{1}=\rho^{*} \mathrm{~A}_{\mathrm{k}}^{*} \mathrm{~V}$

$\mathrm{F}_{2}=\rho^{*} \mathrm{~g}^{*} \mathrm{~A}_{\mathrm{h}} * \mathrm{~S}_{\mathrm{h}}$

$F_{2}>F_{1}$

$A_{\mathrm{h}}{ }^{*} \rho^{*} \mathrm{~S}_{\mathrm{h}}{ }^{*} \mathrm{~g} \geq \rho * \mathrm{~A}_{\mathrm{k}}{ }^{*} \mathrm{v}$

$\mathrm{Sh} \geq(\mathrm{Ak} / \mathrm{Ah}) *(1 / \mathrm{g}) * \mathrm{v}$

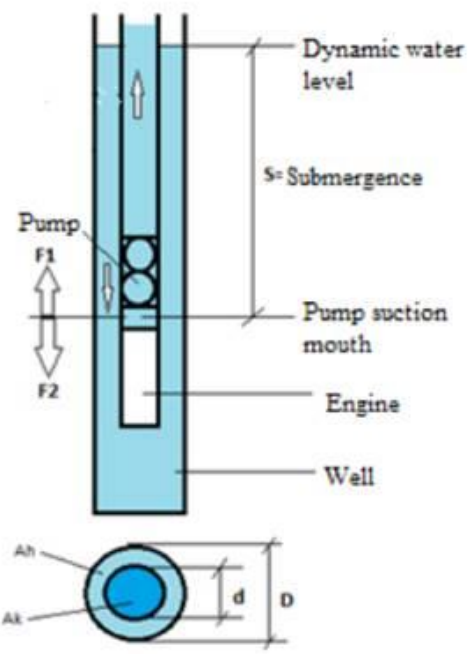

Figures 8

Schematic presentation of moment components effective in equilibrium position

\subsection{Determination of vortex type and submergence vortex}

Two cameras for side-view and top-view were used to view the formation of the vortex. The place of the camera for the top-view was changed according to the water level and the camera angle. A side camera was attached to the pump inlet axis, outside the clear tube, to monitor the vortex formation (Figure 9). Vortex types are classified according to Figure 2 by examining the images taken from the cameras (Knauss, 2017; Papierski et al. 2012). The Submergence vortex $\left(\mathrm{S}_{\mathrm{V}}\right)$ was observed at the moment of vortex formation and video recording was made. Vortex images were taken as images as a result of reviewing the recorded videos.

Figures 9

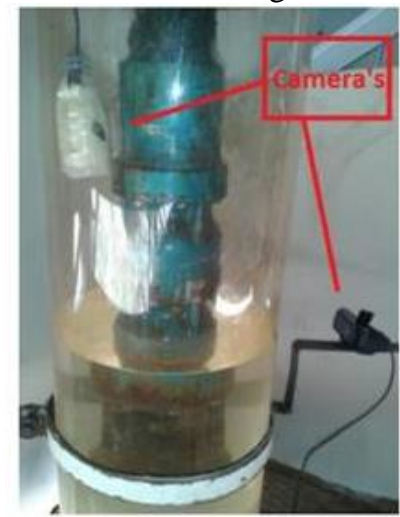

Submersible pump and connection of the camera

\section{Results and Discussion}

The Pe values of the pumps under constant flow rate are presented in Figures 10, 11 and 12 some combinations that will be examples as a function of submergence. Similar graphics were obtained in other combinations. Regression equations were derived from these functions and critical submergence where the Pe pres-sure value is zero was calculated and provided in Table4.

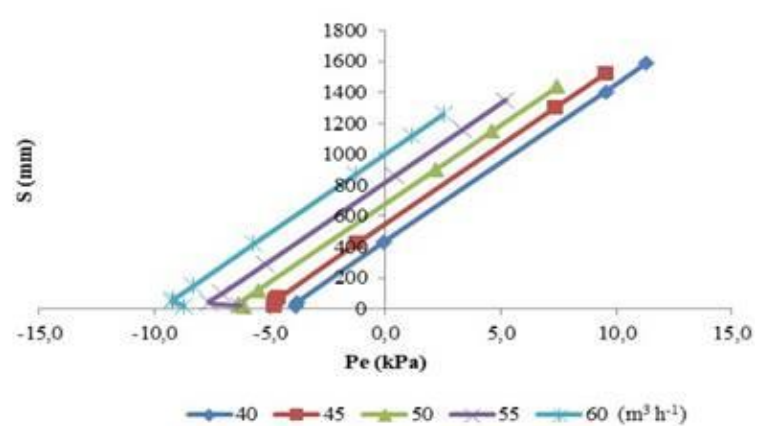

Figures 10

Changes in submergence and inlet pressures of $\mathrm{D}_{1}$ pump at different flow rates and $\mathrm{CS}_{1}$ inlet crosssections

At constant flow rates and cross-sections, critical submergence decreased with increasing pump nominal diameters. Since the column pipe was fixed, well crosssection decreased with increasing pump nominal diameters. Such a case increased water inlet velocity to the 
pump, thus decreased critical submergence. Similar findings were also reported by Hanson (2000) and Christiansen (2005).

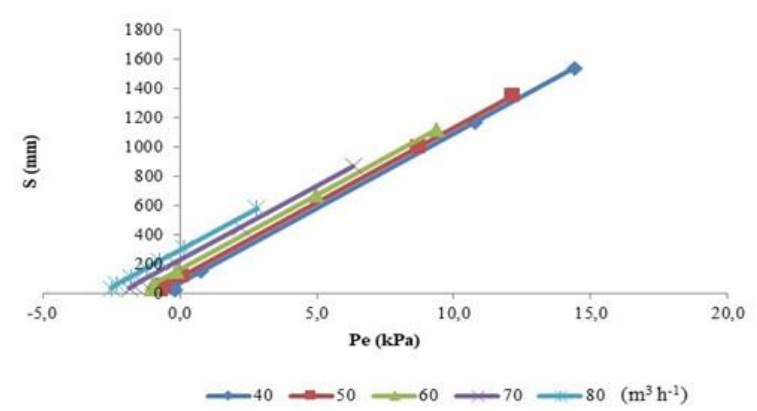

Figures 11

Changes in submergence and inlet pressures of $\mathrm{D}_{2}$ pump at different flow rates and $\mathrm{CS}_{2}$ inlet crosssections

At constant pump nominal diameter, critical submergence increased with increasing flow rates. Most researchers have explained the critical submergence with the number of Froude. They reported that the increase in Froude number increased the critical submergence (Gordon 1970; Möller et al. 2015; Sarkardeh 2017; Sarkardeh et al. 2010). Since the increase in Froude is proportional to the increase in flow rate, in this study the increase in flow rate increased the critical submergence. Pumps reached critical levels earlier at high flow rates. At the same pump nominal diameter, increasing water inlet cross-sections reduced critical submergence. At increasing water inlet cross-sections, outlet pressures at the same flow rates increase and vacuum pressures decrease. Reduced vacuum pressures then caused pumps to reach critical submergence at lower submergence.

Table 4

Critical submergence depth $(\mathrm{Sc})$ values $(\mathrm{mm})$ of submersible pumps at different cross-section and flow rates

\begin{tabular}{|c|c|c|c|c|c|c|c|c|c|}
\hline \multirow{2}{*}{$\begin{array}{c}\mathrm{Q} \\
\left(\mathrm{m}^{3} \mathrm{~h}^{-1}\right)\end{array}$} & \multicolumn{3}{|c|}{$\mathrm{D}_{1}$} & \multicolumn{3}{|c|}{$\mathrm{D}_{2}$} & \multicolumn{3}{|c|}{$\mathrm{D}_{3}$} \\
\hline & $\mathrm{CS}_{1}$ & $\mathrm{CS}_{2}$ & $\mathrm{CS}_{3}$ & $\mathrm{CS}_{1}$ & $\mathrm{CS}_{2}$ & $\mathrm{CS}_{3}$ & $\mathrm{CS}_{1}$ & $\mathrm{CS}_{2}$ & $\mathrm{CS}_{3}$ \\
\hline 40 & 430 & 260 & 186 & 88 & 59 & 48 & 28 & 15 & 10 \\
\hline 45 & 540 & 317 & 231 & - & - & - & - & - & - \\
\hline 50 & 674 & 385 & 284 & 161 & 104 & 75 & - & - & - \\
\hline 55 & 807 & 505 & 348 & - & - & - & - & - & - \\
\hline 60 & 1000 & 593 & 411 & 245 & 153 & 112 & 62 & 36 & 23 \\
\hline 70 & - & - & - & 350 & 223 & 153 & - & - & - \\
\hline 80 & - & - & - & 464 & 290 & 198 & 114 & 68 & 40 \\
\hline 90 & - & - & - & - & - & - & 146 & 82 & 51 \\
\hline
\end{tabular}

\subsection{Submergence vortex and vortex type}

The video camera images recorded at two different axis $\left(\mathrm{C}_{1}\right.$ radial and $\mathrm{C}_{2}$ axial $)$ at different flow rate and submergence throughout the experiments have been investigated. The depths at which vortices begin to form and vortex types are given in Table 5. In the trials, the height at which vortexes began to form was determined as the depth of the submergence vortex $\left(S_{V}\right)$. The vortex types have changed with the continued decrease in the height. Azarpira et al. (2014) stated that different vortex types were formed at different heights.

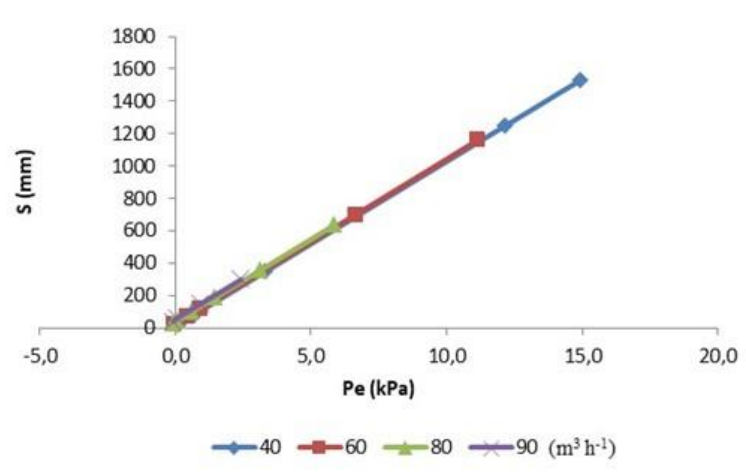

Figures 12

Changes in submergence and inlet pressures of $\mathrm{D}_{3}$ pump at different flow rates and $\mathrm{CS}_{3}$ inlet crosssections

\subsection{Relationship between critical submergence and theoretical submergence calculated}

At the original cross-sections of the submersible pumps, the relationship between critical submergence $\left(\mathrm{S}_{\mathrm{c}}\right)$ measured at different flow rates and the critical submergence calculated $\left(\mathrm{S}_{\mathrm{T}}\right)$ with the developed equations are provided in Table 5.

According to pump inlet pressure measurements, it was observed that while calculated critical submergence $(S T)$ of $D_{1}$ and $D_{2}$ pumps were quite above the determined critical submergence $(\mathrm{Sc}), \mathrm{Sc}$ and $\mathrm{S}_{\mathrm{T}}$ values of $\mathrm{D}_{3}$ pump were close to each other. Therefore, it can be stated that the developed equation was appropriate for narrow well cross-sections. Besides, at constant flow rates, both $\mathrm{Sc}$ and $\mathrm{S}_{\mathrm{T}}$ critical submergence generally decreased with increasing pump nominal diameters.
It has been seen that to occur air inlet continuous in the vortices formed at low submergence $(20-40 \mathrm{~mm})$. These vortices were determined entered type 4, 5 and 6 class. Okamura et al. (2007) emphasized the occurrence of continuous inlet of air at low submergence. The vortex type displayed at high submergence was determined as a cut type (type 1,2,3). Pump performances $(\mathrm{Q}-\mathrm{Pb})$ have fallen in vortex types which the air intake is constant. 
Table 5

In the different flow rates critical submergence, theoretical submergence

\begin{tabular}{cccc}
\hline & $\begin{array}{c}\mathrm{Q} \\
\left(\mathrm{m}^{3} \mathrm{~h}^{-1}\right)\end{array}$ & $\begin{array}{c}\mathrm{Sc} \\
(\mathrm{mm})\end{array}$ & $\begin{array}{c}\mathrm{S}_{\mathrm{T}} \\
(\mathrm{mm})\end{array}$ \\
\hline & 40 & 260 & 43 \\
& 45 & 317 & 55 \\
$\mathrm{D}_{1}$ & 50 & 385 & 67 \\
& 55 & 505 & 82 \\
& 60 & 593 & 97 \\
\hline & 40 & 59 & 26 \\
& 50 & 104 & 40 \\
$\mathrm{D}_{2}$ & 60 & 153 & 58 \\
& 70 & 223 & 79 \\
& 80 & 290 & 102 \\
\hline & 40 & 15 & 19 \\
& 60 & 36 & 42 \\
$\mathrm{D}_{3}$ & 80 & 68 & 75 \\
& 90 & 82 & 95 \\
\hline
\end{tabular}

Different water movements have been observed in the pumps at constant flow rates and different pump nominal diameters. We can explain why different water movements occur, by changing the speed and vacuum values depending on the cross-sectional area of the well and by the different behaviour of water in the narrow area. This case can be explained by reason the fact that the $\mathrm{D}_{3}$ pump with the formation of fluctuation high $(20-60 \mathrm{~mm})$ at the same flow rate and $50 \mathrm{~mm}$ in submergence (Figure 13b) while the $\mathrm{D}_{1}$ pump occurs very little fluctuation high $(5-10 \mathrm{~mm})$ a flow rate of 40 $\mathrm{m}^{3} \mathrm{~h}^{-1}$ and at $30 \mathrm{~mm}$ submergence (Figure 13a).

Some images of the types of vortices are given in Figure 14,15 and 16.

The vortex types at high flow rates and at low submergence have changed according to pumps nominal diameters. In the $\mathrm{D}_{1}$ pump, vortex type 4 formation was observed at flow rates $60 \mathrm{~m}^{3} \mathrm{~h}^{-1}$ and of submergence 50 $\mathrm{mm}$ (Figure 14). In the $\mathrm{D}_{3}$ pump, the vortex formation was detected as type 1 at flow rates $90 \mathrm{~m}^{3} \mathrm{~h}^{-1}$ and submergence $60 \mathrm{~mm}$ (Figure 15). We can explain why different types of vortex are seen that there is not enough space for the vortex to form due to the constriction of the well cross section in the pump with large nominal diameter.

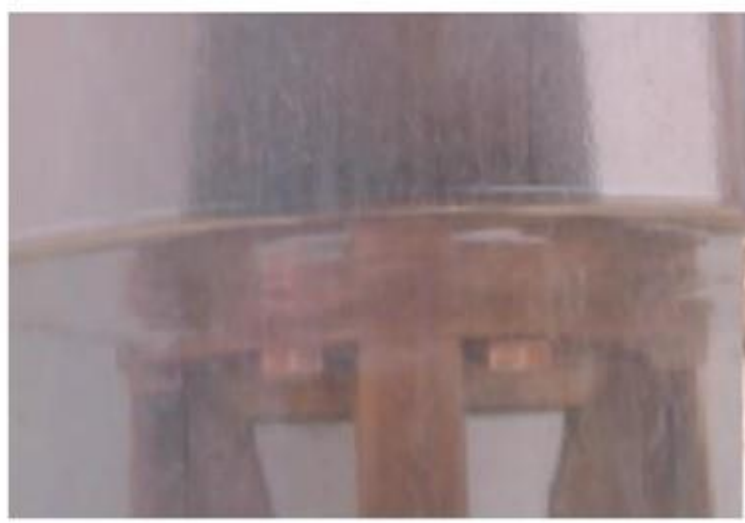

a)

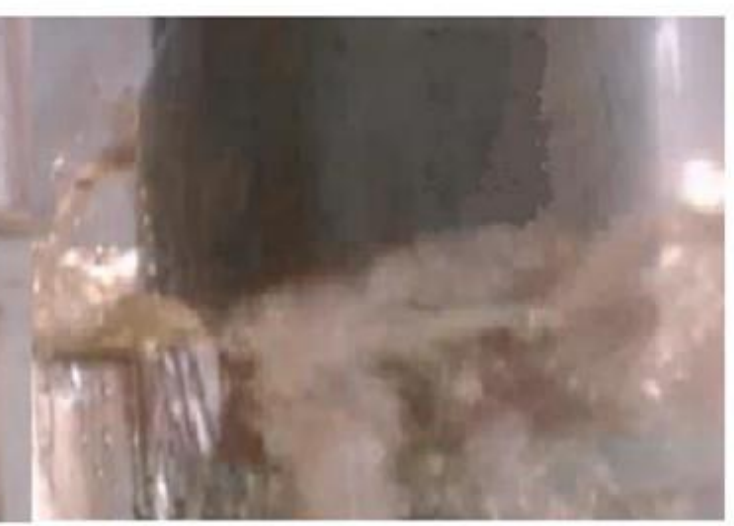

b)

Figures 13

a) $\mathrm{D}_{1} \mathrm{CS}_{3} \mathrm{Q}=40 \mathrm{~m}^{3} \mathrm{~h}^{-1} ; \mathrm{S}=30 \mathrm{~mm}$ b) $\mathrm{D}_{3} \mathrm{CS}_{3} ; \mathrm{Q}=40 \mathrm{~m}^{3} \mathrm{~h}^{-1} ; \mathrm{S}=50 \mathrm{~mm}$

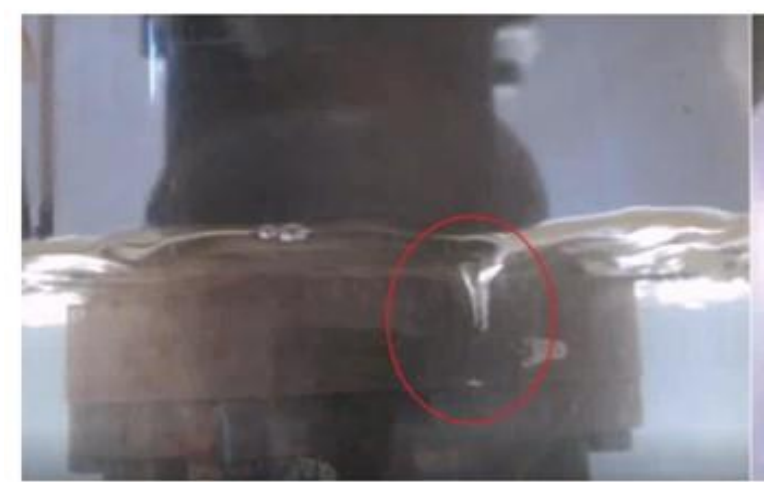

$\mathrm{C}_{1}$

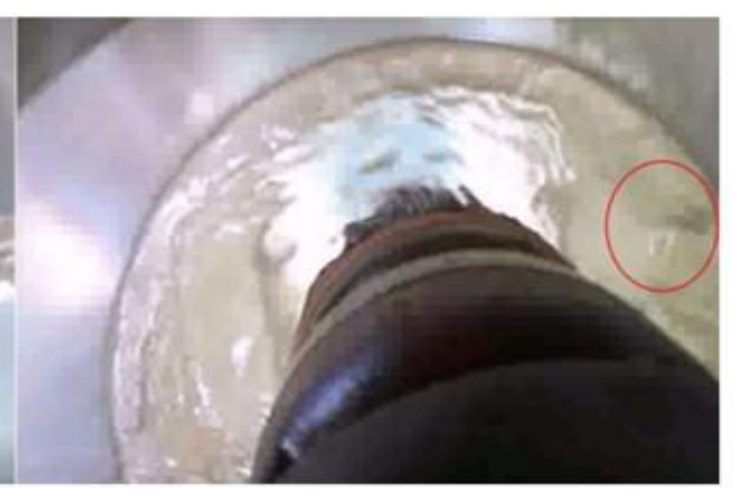

$\mathrm{C}_{2}$

Figures 14

$\mathrm{D}_{1} \mathrm{CS}_{3} ; \mathrm{Q}=60 \mathrm{~m}^{3} \mathrm{~h}^{-1} ; \mathrm{S}_{\mathrm{V}}=50 \mathrm{~mm}$ 


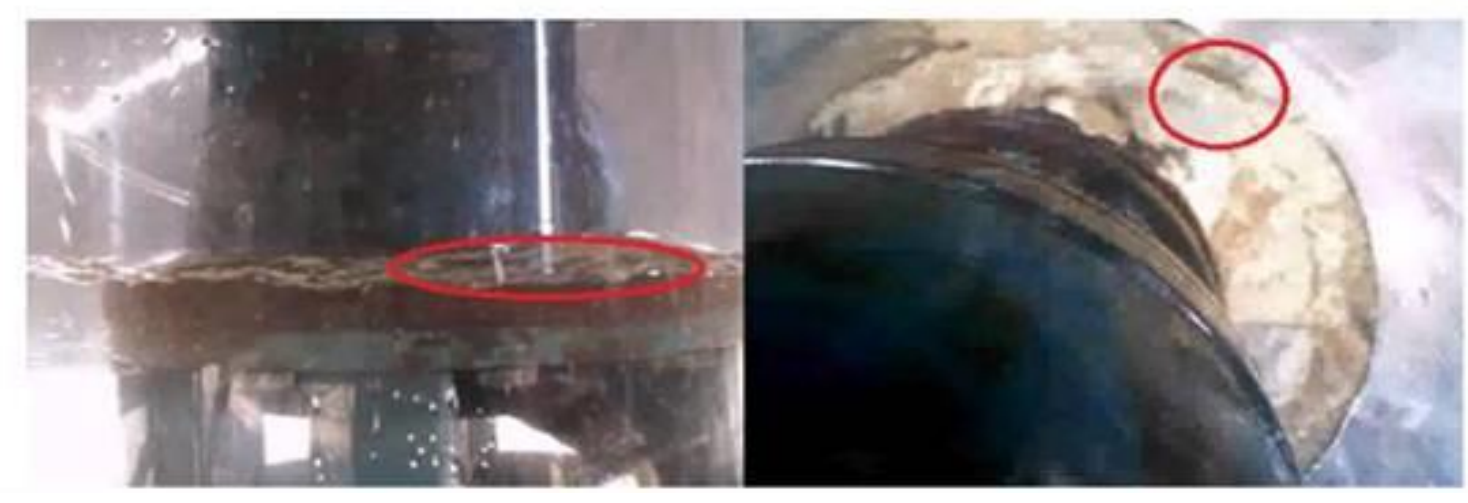

$\mathrm{C}_{1}$

$\mathrm{C}_{2}$

Figures 15

$\mathrm{D}_{3} \mathrm{CS}_{2} ; \mathrm{Q}=90 \mathrm{~m}^{3} \mathrm{~h}^{-1} ; \mathrm{S}_{\mathrm{V}}=60 \mathrm{~mm}$

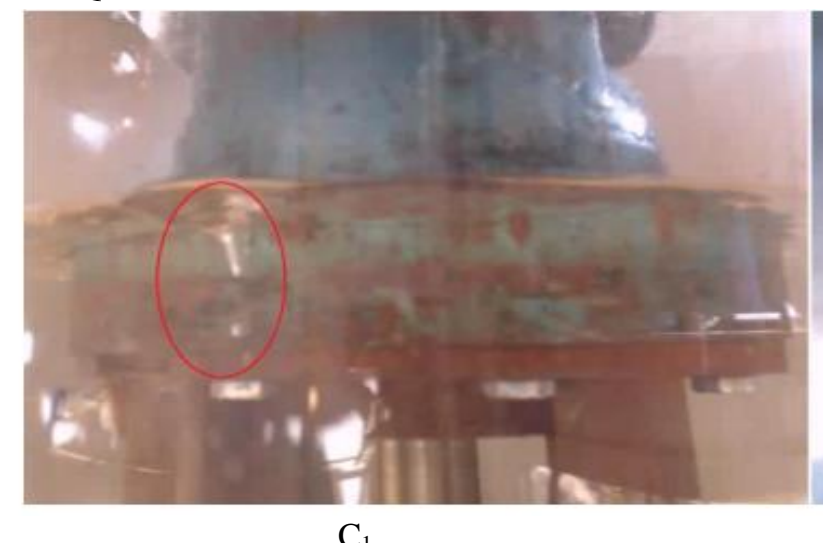

Figures 16

$\mathrm{D}_{2} \mathrm{CS}_{1} ; \mathrm{Q}=70 \mathrm{~m}^{3} \mathrm{~h}^{-1} ; \mathrm{S}_{\mathrm{v}}=60 \mathrm{~mm}$

\section{Conclusion}

Maintenance of a water head over the fluid end of deep well pumps without any reductions in pump performance values is a significant issue for pumping economy and machine safety. Therefore, critical submergence of safe water head just before the generation of a vortex should accurately and simply be determined. In the present study, the vacuum pressure measurement method was proved to be reliably used to determine the critical submergence of submersible pumps.

Critical submergence increased with increasing flow rates at the same pump dimensions. Critical submergence of $\mathrm{D}_{1} \mathrm{CS}_{2}$ combination increased by $8-25 \%$ for each change in flow rate. Such increases varied between $24-38 \%$ in $\mathrm{D}_{2} \mathrm{CS}_{2}$ combination and between $20-62 \%$ in $\mathrm{D}_{3} \mathrm{CS}_{2}$ combination. It can be stated herein that greater flow rates and nominal diameters could be used for the same submergence.

Critical submergence inversely correlated with water inlet velocity into the pump, thus with pump nominal diameter. At the same flow rate, critical submergence of the pumps with low nominal diameter was greater than the values of the pumps with high nominal diameter.

At the same nominal diameters and flow rates, critical submergence of the pumps decreased with increasing water inlet cross-sections. Critical submergence measured at reduced inlet cross-sections decreased about $0.34-0.67$ folds with increasing inlet crosssections.

In practice, submergence usually kept quite high while placing the pumps into the wells. In present pumps, critical submergence were at quite low levels.

Performance losses were observed only at low submergence $(20-150 \mathrm{~mm})$. Therefore, it was thought that there was no need to place pumps into water meters deep and operate. Under constant well equipment and feeding conditions, it is ideal to take dynamic submergence as 2-3 m while installation of the pumps for a safe operation of the pumps.

The formed vortices that form in all pump experiments are usually below the critical submergence levels.

Provided that well equipment and feeding are constant, the relationship between well diameter and pump nominal diameter were considered as a significant parameter for vortex type and critical submergence.

\section{Acknowledgements}

This study was supported by The Scientific and Technical Research Council of Turkey (TUBITAK, 
Project No:213O140). I thank decedent Prof. Dr. Sedat ÇALIŞIR who has contributed to this study.

\section{References}

Ahmad Z, Rao K, Mittal M (2004). Critical submergence for horizontal intakes in open channel flows. Dam Engineering 19:72.

Anonim (2014). For pumps-submersible-clean water. Ankara, Turkish Standards Institute.

Azarpira M, Sarkardeh H, Tavakkol S, Rosha R, Bakhshi H (2014). Vortices in dam reservoir: A case study of Karun III dam. Sadhana 39: 1201-1209.

Chen Y, Wu C, Wang B, Du M (2012). Threedimensional numerical simulation of vertical vortex at hydraulic intake. Procedia Engineering 28: 5560.

Christiansen C (2005). Pumping from shallow streams in: Mines, N.R.a. (Ed.), Natural Resource Sciences p. 2.

Çalışır S, Konak M (1998). Determination of the degree of success in some deep well pumping plants in Konya region, 3. Pump Congress, İstanbul, pp. 69-76.

Eswaran D, Ahmad Z, Mittal M (2007). Critical submergence at vertical pipe intakes. Dam Engineering 18: 17 .

Gordon J (1970). Vortices at intakes. Water Power 137-138.

Hanson B (2000). Irrigation Pumping Plants (UC Irrigation and Drainage Specialist), Department of Land, Air and Water Resources, University of California, Davis.

Hite J, Mih W (1994). Velocity of air-core vortices at hydraulic intakes. Journal of Hydraulic Engineering 120: 284-297.

Khanarmuei M, Rahimzadeh H, Sarkardeh H (2018). Effect of dual intake direction on critical submergence and vortex strength. Journal of Hydraulic Research 1-8.

Kirst K, Hellmann DH, Kothe B, Springer P (2010). Physical Model Investigation of a Compact Waste Water Pumping Station. International Journal of Fluid Machinery and Systems 3: 285-291.

Knauss J (2017). Swirling flow problems at intakes. Routledge.

Möller G, Detert M, Boes RM (2015). Vortex-induced air entrainment rates at intakes. Journal of Hydraulic Engineering 141: 04015026.

Nagahara T, Sato T, Okamura T (2001). Effect of the submerged vortex cavitation occurred in pump suc- tion intake on hydraulic forces of mixed flow pump impeller. http://resolver. caltech. edu/cav2001: sessionB8. 006.

Okamura T, Kamemoto K (2005). CFD simulation of flow in model pump sumps for detection of vortices, Proc. of 8th Asian International Fluid Machinery Conference, Yichang, China.

Okamura T, Kamemoto K, Matsui J (2007). CFD prediction and model experiment on suction vortices in pump sump. The 9th Asian International Conference on Fluid Machinery October 16-19, 2007, Jeju, Korea.

Ott RF (1995). Guidelines for design of intakes for hydroelectric plants. American Society of Civil Engineers, New York, NY (United States).

Papierski A, Błaszczyk A, Kunicki R, Susik M (2012). Surface Vortices and Pressures in Suction Intakes of Vertical Axial-Flow Pumps. Mechanics and Mechanical Engineering 16: 51-71.

Sarkardeh H (2017a). Minimum Reservoir Water Level in Hydropower Dams. Chinese Journal of Mechanical Engineering 30: 1017-1024.

Sarkardeh H (2017b). Numerical calculation of air entrainment rates due to intake vortices. Meccanica 52: 3629-3643.

Sarkardeh H, Zarrati AR, Roshan R (2010). Effect of intake head wall and trash rack on vortices. Journal of Hydraulic Research 48: 108-112.

Schulz H (2013). Die pumpen: arbeitsweise berechnung konstruktion. Springer-Verlag.

Travis QB, Mays LW (2010). Prediction of intake vortex risk by nearest neighbors modeling. Journal of Hydraulic Engineering, 137: 701-705.

Yildirim N, Akay H, Taştan K (2011). Critical submergence for multiple pipe intakes by the potential flow solution. Journal of Hydraulic Research 49: 117-121.

Yıldırım N, Eyüpoğlu AS, Taştan K (2012). Critical submergence for dual rectangular intakes. Journal of Energy Engineering 138: 237-245.

Yildirim N, Kocabaş F (1998). Critical submergence for intakes in still-water reservoir. Journal of $\mathrm{Hy}$ draulic Engineering 124: 103-104.

Yildirim N, Kocabaş F (2002). Prediction of critical submergence for an intake pipe. Journal of Hydraulic Research 40: 507-518.

Yıldırım N, Kocabaş F, Gülcan SC, (2000). Flowboundary effects on critical submergence of intake pipe. Journal of Hydraulic Engineering 126: 288297. 